\title{
Happiness in Communities: How Neighborhoods, Cities, and States Use Subjective Well-Being Metrics
}

\author{
Laura Musikanski \\ Happiness Alliance \\ Carl Polley \\ University of Hawaii \\ Scott Cloutier \\ Arizona State University \\ Erica Berejnoi \\ Arizona State University \\ Julia Colbert \\ Arizona State University
}

\begin{abstract}
This essay, the fourth and last of a series published by the Journal of Social Change, is intended as a tool for community organizers, local policy makers, researchers, students and others to incorporate subjective well-being indicators into their measurements and management of happiness and well-being in their communities, for policy purposes, for research and for other purposes. It provides case studies of community-based efforts in five different regions (São Paulo, Brazil; Bristol, United Kingdom; Melbourne, Australia; Creston, British Columbia, Canada; and Vermont, United States) that either developed their own subjective well-being index or used the Happiness Alliance's survey instrument to measure happiness and well-being. The essay offers lesson to consider when using subjective wellbeing indicator survey instruments. Finally, the essay provides a process for measuring happiness using the Happiness Alliance's survey instrument.
\end{abstract}

Keywords: happiness, well-being, subjective well-being indicators, beyond GDP, subjective wellbeing

\section{Introduction}

This essay is the fourth and last of a series published by the Journal of Social Change that, in combination, form a white paper supporting the happiness movement. A key feature of the happiness movement is the adoption by policy makers of wider measures of well-being in lieu of reliance on economic measurements. In this essay, we explore the use of happiness indicators by communities, cities, and states. The first essay of this series, "Happiness in Public Policy" (Musikanski, 2014), explored examples of policy promulgated for the purpose of citizen happiness by national government, and it included a policy screening tool modeled after that used by the Bhutanese government. The second essay, "Measuring Happiness to Guide Public Policy Making: A Survey of Instruments and Policy Initiatives" (Musikanski, 2015), considered the question of whether happiness can be measured and how to measure it. The third essay, "Life, Liberty, and Pursuit of 
Happiness: Measuring What Matters" (Musikanski \& Polley, 2016) surveys efforts in various nations to measure happiness and use the data for policy. The intent of this essay is to provide guidance to community organizers, policy makers, researchers, students, and others using subjective well-being indicators to measure and manage happiness and well-being.

\section{The Basis for Community Happiness}

\section{Money Matters...Up to a Point}

Dan Ariely (2010) told a story about when he was a professor at the Massachusetts Institute of Technology. His performance was measured by a set of indicators that led him to spend less time with students while ignoring the potential of gains to his own happiness and financial status. Ariely explained his experience: "human beings adjust behavior based on metrics they're held against. Anything you measure will impel a person to optimize his score on that metric. What you measure is what you'll get. Period" (p. 1). Since the end of World War II, gross domestic product (GDP; the sum of all goods and services produced in a year) has been the "ultimate measure of a country's overall welfare" (Dickenson, 2011, p. 1).

People living in countries with higher GDP tend to be happier (Giovannini, Hall, \& d'Ercole, 2007). Countries with high GDP are more resilient to crisis (Helliwell, Huang, \& Wang, 2015), and citizens of such countries generally have better education, better physical health, higher rates of employment, more equitable income distribution than countries having a lower GDP, and more social cohesion (Giovannini et al., 2007).

Money matters, but only up to a point. Although increases in income lead to increases in happiness for developing countries, in contrast, as poor and developing nations become richer, happiness does not, as a rule, follow (Easterlin, 1974, 1995, 2001; Layard, 2007). At the same time, increases in GDP worldwide entails unsustainable levels of consumption, natural resource depletion (SERI, Global 2000, \& Friends of Earth Europe, 2009), and waste (Hoornweg \& Bhada-Tata, 2012).

In 2009, French President Nicolas Sarkozy called on governments to measure well-being and use the data for national policy (Aldrick, 2009). Since then, a growing number of national governments have been exploring subjective well-being indicators and data collection (Musikanski \& Polley, 2016).

Indicators are measurement tools that yield data about the condition of that which is being measured. Other terms used synonymously with indicators are metrics, measurements, and index. In some cases, when more than one aspect of a condition or more than one thing being measured is combined, it is called an index. For the purposes of this essay, the terms indicator or index are used for all projects described.

\section{Metrics Matter}

At a national level, for policy makers, the adoption of well-being indicators met barriers ranging from media mistrust to lack of understanding on the part of policy makers on how to use well-being data (Whitby, Seaford, Berry, \& BRAINPOoL Consortium Partners, 2014). At a community level, there has been significant application of, and research on, indicators of well-being. The Community Indicators Consortium (2015), a nonprofit that coordinates community-based indicator efforts, lists 300 community indicator projects on its website. Fiksel, Eason, and Fredrickson (2011) have compiled over 6,000 sustainability indicator sets used at varying levels, from international institutions to local communities. Until recently, the majority of indicator projects are composed of 
objective indicators. There is a need for "richer and more human" (Davidson, 2015, p. 10) data for use by policy makers.

Since approximately 2008, communities worldwide have been exploring, collecting, and using happiness and well-being data through the use of subjective well-being (i.e. happiness) indicators. For many of these communities, data collection domains are quite similar to sustainability and quality-of-life indicator sets, but differ as the methods are through survey instruments. Subjective well-being indicators entail the use of survey instruments and often measure affect, eudemonia, and satisfaction with life as well as satisfaction with conditions of life (also called domains) often measured by sustainability and quality-of-life indicators.

The remainder of this essay explains five community-based efforts to measure happiness and wellbeing with subjective well-being indicators. The five community-based case studies are intended to be illustrative, not comprehensive. In each community, the subjective well-being indicators included widely defined aspects of economic, environmental, and social conditions as well as affect (feelings or emotions), eudemonia (from the Greek eu for good and demonia for soul, connoting a sense of purpose, belonging, value, and meaning within the contexts of one's personal life, community, and society, and today often translated as thriving or psychological well-being), and satisfaction with life (a reflective question about one's sense of satisfaction with how one's life has gone).

\section{Community-Based Efforts to Measure Happiness}

This section covers five community efforts to measure and manage happiness and well-being using survey instruments: São Paulo, Brazil; Bristol, United Kingdom; Melbourne, Australia; Creston, British Colombia, Canada; and Vermont, United States. The processes and parties involved in the community-based effort are explained, and each explanation concludes with a brief analysis.

\section{São Paulo, Brazil}

In São Paulo state, communities and cities may have been the first to follow the nation of Bhutan's lead in using a Gross National Happiness (GNH) or Felicidade Interna Bruta index. Under the leadership of Susan Andrews and Instituto Visão Futuro (IVF), a nonprofit, several communities have been experimenting with subjective well-being indicators of since before the release of the first World Happiness Report (Helliwell, Layard, \& Sachs, 2012). The IVF developed a subjective wellbeing index that has been used in various communities to collect data, inform decision making, and guide allocation of resources (Helliwell, Layard, \& Sachs, 2013). The index covers the domains as defined by Bhutan's GNH Index: "living standard, governance, environment, culture, education, time use, psychological well-being, health, and community" (Nesh Fotos e Videos, 2012, m. 1:38).

The IVF's suggestions for measuring and managing happiness and well-being comprise 11 activities (translated and synopsized here).

Activity 1: Local leadership (academic institutions or nonprofits) identifies a neighborhood and partners to participate in the project.

Activity 2: Working with a local school, local leaders select and train younger (elementary and middle school students) children as "Doctors of Joy," (IVF, n.d., p. 4) thereby increasing the children's awareness of "universal values of kindness, generosity, gratitude and cooperation" (Nesh Fotos e Videos, 2012, m. 3:55) and providing the community a context for the project in terms of happiness, sustainability, and love (Nesh Fotos e Videos, 2012, mm. 11:36-11:31). 
Activity 3: Local leaders select high school teachers at the local school to be coaches. They teach coaches how to train the youth (high school students) to conduct the GNH survey in the selected neighborhood.

Activity 4: Students and teachers conduct the GNH survey, collecting enough responses to compose a random sample, as determined by local leaders.

Activity 5: Local leaders analyze GNH survey results and create a report.

Activity 6: Schools and local leaders release the survey results and invite the people in the neighborhood to a community meeting to discuss the results.

Activity 7: Youth and coaches conduct a world café style meeting with the community in which local leaders explain survey results, the community gives feedback, youth gather community feedback, and children perform as "Doctors of Joy" (IVF, n.d., p. 4).

Activity 8: Local leaders partner with local government to analyze, and take action based on community feedback.

Activity 9: Local leaders partner with local businesses, if appropriate, to implement action suggested by the community and decided upon by local government.

Activity 10: Local leaders partner with a local university to conduct various activities and to ensure continuity.

Activity 11: Continued involvement of community members, youth, and other partners builds on the success of the project (IVF, n.d.).

Not all of these 11 activities are sequential. For example, partnerships with businesses, local government, or university may be formed at any point during the project.

In one neighborhood, where water was identified as the priority after surveying the community and a discussion of the results was held with community members, the Bank of Brazil partnered with the community to build 50 biodigester septic tanks (O'Donnell, 2013). In another neighborhood, after a survey was conducted and results discussed, community members determined that a soccer field was necessary for the safety and happiness of youth, which city officials then built and supported (Nesh Fotos e Videos, 2012).

The efforts to measure and manage happiness and well-being in São Paulo are exemplary in many ways. The projects have tremendous potential to lead other areas around the world based on their successful examples, which involved city governments, schools, university academics, and volunteers on an ongoing basis (Helliwell et al., 2013). Considering the use of the GNH in São Paulo state, O'Donnell (2013) said, "In Brazil, GNH starts with indicators, but the questionnaire is simply the launching pad to generate a high level of citizen participation in collective discussions and concerted action..." (p. 102). The depth and duration of collaboration between academics, local policy makers, neighborhoods, nonprofits, and schools demonstrate levels of collaboration and partnership that allows for successful and meaningful implementation of the projects. The projects expand over a time frame that allows for community involvement and ownership over the process and outcomes. Many resources, from time to expertise, are devoted to these projects by the various collaborators. The outcomes of these projects are tangible and result in an increase in community assets. 
While these projects are exemplary, there is little information published or produced about them in English or other languages than Brazilian Portuguese, and only a few researchers, community organizers, and policy makers know about the process or success of these projects. This may be one reason that the leadership potential for these projects, which could inspire other neighborhoods and cities around the world, has not been realized.

\section{Bristol, United Kingdom}

In Bristol, Happy City, a nonprofit, launched a survey as part of its Happy City Index program in 2015 (Happy City, n.d.). The initial survey included questions on affect, community, eudemonia, health, satisfaction with life, social support, time balance, and work (Happy City, n.d.). In 2016, they reissued the survey, as part of a project called the "Happiness Pulse" (Happiness Pulse, n.d.). The reissued survey had a total of 30 questions covering the domains of education, eudemonia, health, satisfaction with life; 20 questions focused on social support; and an additional 10 questions covering the domains of access to nature, community, culture, health, housing, psychological well-being, transportation, and work, in addition to demographic questions (Happiness Pulse, n.d.).

The initial goals of the project included measuring city-wide happiness, providing trainings to individuals, educating policy makers, and offering a replicable model to other cities (Local Giving, 2015). Happy City's Happy City Pilot Policy Report (S. Wren-Lewis, personal communication, July 17, 2015) anticipated policies relevant to the data they planned to collect. Some of the suggested directions for policy makers and community programs in the report included prioritizing (a) access to formal and informal education over income, (b) employment over income, and (c) health over employment and income. Other suggestions include (d) increasing work-life balance and reducing commute times, (e) assessing cultural policies in terms of well-being impacts, and (f) fostering a sense of place in terms of relationships with loved ones, social interactions, trust, a sense of belonging, and intergenerational connections (S. Wren-Lewis, personal communication, July 17, 2015).

In 2016, Happy City issued a report analyzing the data gathered from a convenience sampling in the city of Bristol. The survey was conducted online and, while not enough data was gathered to ensure a fully representative sample of the various neighborhoods across the city, the report focused on ways that survey data could be useful. It also compared the data gathered to data previously gathered by other institutions (Happy City, 2016a).

In 2016, Happy City also released a report called the Happy City Index about nine U.K. cities (Birmingham, Bristol, Leeds, Liverpool, London, Manchester, Newcastle, Nottingham, and Sheffield), focusing primarily on objective measures. The report covered the domains of community, education, health, place, and work, using 60 indicators (Happy City, 2016b). The two projects were conducted in tandem.

Happy City's coupling of survey data with objective data is an important conceptual framework. One project focuses on citywide measures and the other on neighborhood level scores. The two projects come under separate names and have separate reports. Because the Happy City Index program reports data for cities and the Happiness Pulse program reports data for neighborhoods, it appears these two efforts are separate projects, each requiring potentially competing resources. If Happy City were to find a way to conjoin the two data sets, both the subjective data from the Happiness Pulse and the objective data from the Happy City Index, into one geographic region, and work with that region's policy makers and community organizers to deliver tangible outcomes, the project could provide exciting leadership advancing the happiness and well-being movement. 


\section{Melbourne, Australia}

In Melbourne, the Australian Unity Community Well-Being Index is a survey instrument that the Australian Center on Quality of Life at Deakin University and Australian Unity, a company formed and used to collect data since 2001 (Australian Centre on Quality of Life, n.d.b). The survey covers the domains of community, health, satisfaction with life, security, social support (relationships), spirituality, and standard of living (International Well-Being Group, 2013) as well as affect and eudemonia (Australian Centre on Quality of Life, n.d.c).

Australian Unity (n.d.), an insurance and investment company, uses the data for business purposes, and to conduct community outreach that includes discussion of the data at the community or group level. The Australian Centre on Quality of Life (n.d.a), an academic institution, helps gather the data and provides it online for free to researchers for academic purposes.

What sets the Australian Unity Well-Being Index apart is how long it has been in operation. One of the reasons it has persisted may be the public-private partnership between the company and academic institution, with each providing resources and reaping benefits from the data in different ways.

The Australian Unity Well-Being Index measures national level well-being and happiness only, and is not being used at a state, city, or neighborhood level beyond Australian Unity's community outreach. The Australian National Development Index (ANDI) is another effort underway in Australia that may result in state, city, and neighborhood level data. ANDI is a collaborative effort that includes Deakin University, foundations and nonprofits, the Australian government Bureau of Statistics, and other organizations (M. Salavris, personal communication, December 1, 2015). The goal of ANDI is to annually collect a national sample of 500,000 individuals that will provide representative data for various government bodies at all levels, create annual reports, and track progress. ANDI covers the domains of community, culture, education, economy, environment and sustainability, governance, health, indigenous well-being, leisure, life satisfaction, social justice, youth well-being, work, and work-life balance (ANDI, 2017).

The national level Australian Bureau of Statistics is a partner in the ANDI project and, as such, is working with other organizations, from universities to foundations. The relationship is inspiring, as other national level government agencies that measure happiness and well-being generally have not done so in collaboration with nongovernmental organizations (Musikanski \& Polley, 2016). If the ANDI project were to succeed; and to include both subjective and objective data including measures for affect, eudemonia, satisfaction with life, and satisfaction with the conditions of life that encompassed the domains of well-being and happiness; and if the data were used by local governments for policy purposes, the result would be a vanguard project and a significant step toward the realization of the happiness movement.

\section{Creston, British Columbia, Canada}

In Creston, city and municipal governments joined with local nonprofits and companies to conduct a survey of the area using the Happiness Alliance's survey instrument. The survey instrument measures affect, eudemonia, and satisfaction with life, as well as the domains of affect, community, culture and arts, education, environment, government, health, social support, standard of living, time balance, and work. 
The goal of the Creston project was to compete against other regional governments to gain funds to enhance quality of life (Creston and District Community Directed Funds, n.d.a). The data was used to identify how to allocate funds for economic development that enhanced quality of life. It was shared with the community through community meetings, press releases, and the issuance of a report online and in paper so community organizations and people could use it to enhance the wellbeing of the area (Creston and District Community Directed Funds, n.d.a). The project was successful in its goal of winning funds.

The project was undertaken in eight sequential steps portrayed in a poster created by the Creston and District Community Directed Funds Committee, and presented at the 5th Organization for Economic Cooperation and Development (OECD) World Forum on Statistics, Knowledge, and Policy Transforming Policy, Changing Lives (see Appendix B):

Community Directed Funds: Formation of the Creston and District Community Directed Funds Committee composed of civil society groups, local governments, and First Nations with the common goal of getting funding

The Better Life Project: Naming and expansion of the project to include civil society groups, such as the library, post office, farmers market, and museum (Creston and District Community Directed Funds, n.d.b)

Joining the Happiness Movement: Benchmarking to other areas; the decision to use a happiness model

Indexing GNH: Determination to use the Happiness Alliance's Happiness Index survey instrument, and to engage volunteers in the implementation of the survey for data collection

A Wave of Participation: Survey conducted with media support; conducting the survey over a 10-day period with media support, and with over 100 volunteers who conducted outreach to vulnerable communities to implement the survey

Our Happiness: Analysis of data and creation of a report by a nonprofit member of the Creston and District Community Directed Funds Committee

Reflecting on the Results: Report on the data issued online, at community events and at a dedicated stakeholder meeting with facilitated dialogue among the public about using the data to inform decisions and action

Happy and Well From Yahk to Riondel: Practical use of data results; Creston and District Community Directed Funds Committee used the data to identify needs and assets, local community organizations used the data to inform action, and businesses used the project to market the area to tourists (Creston and District Community Directed Funds, n.d.c)

The Creston project offers a model project flow chart for other areas and a good example of how to use media effectively. The members of the committee were able to build a robust media campaign, and the project was covered by almost every media channel in the area. The Creston and District Community Directed Funds Committee used the Happiness Alliance's survey instrument, and so was able to use the data gathered by that organization to compare their own results. The project benefited from a serendipitous coincidence in that the local school district had conducted a random sample for a survey with analogous indicators, thus providing a comparison data set that validated their project findings. 


\section{Vermont, United States}

In Vermont, Gross National Happiness USA (GNHUSA), a nonprofit, conducted a convenience sampling of the state of Vermont using the Happiness Alliance's survey instrument in 2011 (GHNUSA, n.d.). GNHUSA used the survey in 2011 to generate conversation and interest. The following year, in 2012, GNHUSA joined forces with the University of Vermont Center for Rural Studies to conduct a random sampling of Vermont using the Happiness Alliance's survey instrument (GHNUSA, n.d.). The random sampling was funded by a single donor, and the university provided the analysis of the data. A report was issued in 2012 (Center for Rural Studies at the University of Vermont, 2012). The data collected by the random sampling was compared to the entire data set collected by the Happiness Alliance.

Following the report, GNHUSA convened policy makers and nonprofit leaders in a data laboratory (Common Good Vermont Coordinator, 2012) where policy makers and community organizers were taught how to use the survey data and to consider results-based accountability (T. Barefoot, personal communication, May 30,2014). The data were also included in a statewide database called Building Bright Futures, which was created to inform policy makers about issues related to children's wellbeing (K. Paterson, personal communication, May 29, 2014).

In 2016, the University of Vermont Center for Rural Studies, working with Barefoot, set plans in motion to conduct a second random sampling of Vermont. Again, the organization planned to use the Happiness Alliance's survey instrument (M. Moser, personal communication, August 11, 2016) to measure progress compared to the prior data set for towns and communities in the state of Vermont (T. Barefoot, personal communication, May 30, 2014).

Vermont's use of random sampling for a geographic region makes its efforts a good example for other areas. A random sample yields data that policy makers can defensibly rely on, where a convenience sample does not necessarily guarantee representative results. Vermont also sets an example by being one of the first areas to convene policy makers and teach them how to use survey-based subjective well-being data.

\section{Lessons From Community-Based Efforts}

Each of the efforts described in the section above demonstrate different and important lessons for communities measuring and managing happiness. In addition to these five examples, there are other noteworthy examples (see Appendix A) that reinforce the lessons explained below. This section identifies lessons learned from the efforts described above and in other areas, concluding with a list of best practices. To ensure the success of an effort to measure and assess happiness, project leaders should consider (a) flexibility in the use of language, (b) mindfulness of the social-political climate, (c) ability to gather political will in support of the project, and (d) availability of resources, particularly diverse sources of non-monetary resources and volunteers, to promote project success and resilience. The sections below support these claims.

\section{Flexible Terminology and Cultural Relevance}

In any project associated with measuring or assessing happiness, language is fundamental to project success. The term happiness can impede or foster the success of project, depending on the local culture. In the United Kingdom, the media and political parties objected to use of the word happiness (Whitby et al., 2014, p. 8) causing the national government to replace the term Happiness index (BBC, 2013, p. 1) with measuring national well-being (Office for National Statistics, n.d. p. 1). In Bristol, the term happiness is used in spite of this, but with the understanding the efforts are local 
and community-driven. The project in Creston was called the Better Life Project, instead of using the term happiness. Santa Monica's project terminology also changed from happiness to well-being. In municipalities in Mexico, the word happiness is used widely to describe projects involving the use of subjective well-being indicators.

Religious belief and culture are also important to consider with terminology choices. For Buddhists, happiness is conceived as sukha (translated as ease, bliss), a state that emerges through balance and awareness (Walsh, 2013). In Chinese, meanwhile, xingfu is the translation for happiness that is used in the term xingfu zhishu (translated as Gross National Happiness). Xingfu refers to a state of good fortune arising from external circumstances and interpersonal relationships. This can be perceived as very different from the Western concept of happiness, where happiness is an object to be pursued or found individually (Polley, 2012). Western psychological instruments are generally reliable and cross-culturally valid for measurement of subjective well-being in China (Zhang \& Norvilitis, 2002). However, comparisons between measurements of subjective well-being among Chinese and Western populations are not entirely straightforward, due to a potential cultural response bias in which, for example, commonly held beliefs relating to Confucian and Taoist philosophy lead to different concepts of modesty, and different interpretations. In Brazil, culture also plays a role in terminology decisions. Many Brazilians struggle in regards to their standard of living, health, and education (World Bank, 2015), yet they are known to be a happy people nonetheless ("Brazil Isn't Growing," 2013). This may be because the cultural values are different from those of Northern America. In the IVF's GNH/FIB projects, happiness is linked to love and the concept of sustainability (Nesh Fotos e Videos, 2012), rather than wealth and status.

Investigation into the basis of cultural belief systems, and how they relate to human needs, and how they translate into happiness and well-being indicators may be warranted when measuring happiness and well-being at a community level in various cultural settings. With these differences in mind, it is important that the questions to gather data about affect, eudemonia, and satisfaction with life, as well as the conditions of life, measure comparable concepts that reflect universal human needs. This can be ensured, in part, through accurate translations in different languages of happiness survey questions.

Some misinterpret the issue of cultural relevance to mean that affect, satisfaction with life and the conditions of life, and eudemonia have lesser or more importance depending on the culture, and so happiness and well-being indicators should measure different things depending on the culture. If this were the case, then in the United States, a survey instrument measuring subjective well-being may include questions about material well-being and work, but not necessarily include questions about arts and culture, community, and the environment, and in Brazil, the opposite might be the case. This is confusing basic needs and rights, which transcend boarders and time (Maslow, 1943; Max-Neef, Elizalde, \& Hopenhayn, 1992) with cultural values, which change over time and differ across geographies. All people have basic and higher needs, ranging from sustenance and shelter to freedom and self-actualization (i.e. realizing one's full potential), and the well-being of everybody on the planet is dependent upon a healthy environment. Moreover, culture may place a higher value on a condition of life, such as wealth, consumption and status, at the detriment of people's happiness and well-being.

The use of the term happiness or well-being raises a question about the differences and similarities between types of indicators used to address quality of life, well-being, happiness, sustainability, and progress beyond GDP. Some claim that one of the most important distinguishing factors is whether an indicator is survey-based (happiness indicators) or objective (well-being indicators). Others claim it depends on whether the goal of collecting data is to inform policy (well-being or beyond GDP 
indicators) or not. The differences may be merely semantic or politically motivated. One factor that most all of those using the various terms and indicators have in common is that they share the goal of broadening the use of indicators for economic and social policy whereby public policy is more closely tied to people's happiness, well-being, quality of life, and planetary sustainability.

The lesson to be learned regarding terminology is that local leaders should stay focused on the goals of an effort, and be flexible in response to a community's reactions and circumstances with regard to terminology. The lesson to be learned regarding cultural relevance is to ensure that the basic concepts and questions in a survey instrument reflect the needs that all humans share in common, and that if questions in a survey instrument are translated, the terminology conveys comparable meaning.

\section{Supportive Political-Social Climate}

The political-social climate can have a substantial impact on a happiness project. The national government of the United Kingdom was among the first in the Western world to develop and use happiness or "well-being" (Dundee, 2014, p. 9) indicators within the context of the happiness and beyond GDP movement. The U.K. Office of National Statistics regularly gathers and publishes subjective and objective happiness and well-being data, thereby setting a national context for community effort. With the national government measuring happiness and well-being, the idea of measuring happiness is not foreign or new. Funding of local projects is part of the national government's efforts (Big Lottery Fund, n.d.). This lays a rich foundation for community-level work. Resources that would otherwise be needed to raise awareness, educate, and inform people about what happiness and well-being metrics are and whether happiness can be measured, can instead be used in other ways. The availability of resource to conduce a variety of projects in Bristol may be in part because of the social-political climate.

The lesson regarding political-social climate is to tailor the goals of an effort to the circumstances of the community. If the concept of measuring and managing for happiness and well-being is new and unknown to the community, then an effort to measure happiness might be more productively framed as a way to open dialogue, rather than inform policy makers, as was done in the first use of a survey instrument in Vermont.

\section{Political Will}

The political environment can influence whether a happiness project will be lasting or a one-time event, as well as the extent of the project's impact on policy. If an effort is dependent upon political will, it may be vulnerable to political changes. The project in Guelph (see Appendix A) provides an example of how detrimental the loss of political will can be. After an election, the new mayor ended the city's efforts to measure and manage happiness and well-being. Every trace of the project was removed from the city website on the new mayor's orders (B. Smale, personal communication, October 16, 2016).

In contrast, when efforts are undertaken by multiple entities with different interests that derive various benefits from the project, the effort may have a greater chance at longevity. In Melbourne, the dearth of subjective well-being data collected by the national government spurred the Australian Centre on Quality of Life's (n.d.c) efforts. In São Paulo state and municipalities of Mexico, academic institutions engage in research while partnering with local governments and community organizations. These partnerships helped ensure the efforts had an impact on policy makers, and did not fizzle if political will were to wane. 
The lesson regarding political will is twofold. Like the lesson regarding the political-social climate of a project, it is important to tailor the goals of a project to the circumstances of the community. The second lesson is to involve enough community organizers and organizations that the effort is not entirely dependent upon one entity, and so can survive the withdrawal of support from any one partner.

\section{Adequate Resources}

Some of the most valuable resources in community-based efforts are the community organizers themselves. It is important to have a diversity of community organizers, each able to give their unique contribution and gather a benefit from participating in the effort. The project in Melbourne, whereby an academic institution and business each derive value from gathering data, is a good example of this. Creston's effort demonstrates how media can be an invaluable resource. When diverse collaborators are fully engaged in a project, a media plan is likely to emerge and be implemented through the group's experience and connections. Projects in Victoria, British Columbia, Canada, and Seattle, Washington, United States, also provide examples of this (see Appendix A).

Community-based efforts tend to draw heavily on volunteers and other non-monetary resources. When these run out, the efforts do too. Most efforts in North America are examples of institutional and individual volunteers successfully implementing projects in the short term but not the long term. In these projects, inadequate resources, both monetary and nonmonetary, resulted in the projects floundering. The happiness projects in São Paulo state and Melbourne are in stark contrast, where institutional dedication has kept happiness projects alive for a long time.

The lesson regarding resources is to convene partners who will give, and gain unique resources from the project on a continual basis. It is also important to involve media support through as many channels as possible.

\section{Summary of Lessons Learned}

As mentioned above, optimally, community-based effort to measure happiness should have the following components: (a) flexible terminology and cultural relevance, (b) supportive political-social climate, (c) political will, and (d) adequate resources. This is not to mean that a community-based project must have all of these components to be a success, particularly in the short term. Rather, communities can draw on this essay and the examples within to determine the scope and purpose of their own effort to measure and manage happiness and well-being in their community. Ultimately, short-term projects seed the future for longer-term projects, and are also crucial to the development of the happiness movement.

\section{How to Use the Happiness Alliance's Happiness Index}

A community organizer, policy maker, researcher, student, or other person seeking to measure happiness and well-being has three choices: (a) develop a unique set of indicators, (b) use the same indicators of another area or organization, or (c) adapt an established set of indicators. The second two options contribute towards the standardization of indicators, which allows for comparisons between areas and over time. Comparability is an important factor in relation to one of the goals of the happiness movement: the adoption by policy makers of happiness and well-being indicators in lieu of a singular focus on GDP. The first and third option allows for harmonization, by which different areas use different indicators to measure different aspects of an area's conditions. The third option allows for both standardization and harmonization. 
The Happiness Alliance is a nonprofit that has been providing a happiness and well-being index to communities since 2011. Its mission is to improve the well-being of society by increasing understanding and appreciation of the factors that lead to life satisfaction, resilience, and sustainability. The Happiness Alliance provides a freely available subjective well-being survey instrument, called the Happiness Index (also called the GNH Index), as an online tool at www.happycounts.org. It has been translated into many languages, including Arabic, Brazilian Portuguese, Chinese, French, Italian, Japanese, Korean, and Spanish. The subjective well-being index has been scientifically validated internally and externally, and can be customized by adding questions (Musikanski et al., 2017). It has been used to measure the well-being of populations ranging from small informal groups to states and countries. Examples of communities that have used the Happiness Alliance's survey instrument can be seen at the OECD Wiki-Progress site (http://wikiprogress.org/data/organization/happiness-alliance).

The Happiness Alliance also provides collateral support for use of the survey instrument. These include access to an entire data set from over 65,000 respondents to researchers, community organizers and others aligned with the mission of the organization so long as they sign an agreement to protect personal data (although profile information is never shared). In addition, explanations and tools for community organizers using the survey instrument are freely available at http://www.happycounts.org/happy-community-toolkit.html.

When measuring happiness and well-being, each effort will unfold in its unique way in response to its unique circumstances. When undertaking the measurement of happiness and well-being with the intent of encouraging policy makers to use wider measures of well-being, in addition to the lessons outlined above, several key factors should be kept in mind: (a) know the purpose of the project and ensure the purpose is realistic in the political-social climate of the project, (b) start small or conduct a trial run with a test group, (c) involve community members and organizations with a continually open door, (d) develop a robust and community-driven media plan before launching the survey instrument, (e) develop and implement a plan for analyzing and reporting the data that involves the community members and the public at large, and (f) have a long-term vision for the project and communicate it within the community and outside of it.

The Happiness Alliance and other organizations like it are in support of the measurement of happiness to support communities in the transition toward a sustainable future and to encourage local and national policy makers use of wider measures of well-being in lieu of GDP or analogous local economic metrics. The different uses of a subjective well-being survey described in this essay are just a few of the ways to contribute to the happiness movement. It is hoped this essay will inspire further development of the uses explained, as well as new uses of subjective well-being survey instruments measuring happiness and well-being. It is also hoped that this essay will inspire more community organizers, policy makers, researchers, students, and others to join the happiness movement in transforming governments and society so that happiness, well-being, resilience, and sustainability become the primary driving force and goal for all nations, communities, and people.

\section{Conclusion}

Cities, states, and communities around the globe are measuring happiness and well-being in order to gain insight on current happiness and well-being levels, gather data to inform policy, promote greater well-being and happiness, and contribute towards the use of wider measures of well-being. This essay focused on five examples of states, cities, and communities that are leading the way with respect to happiness measures and assessment, and described many others. This essay was written to explain examples of community projects measuring happiness and well-being and inspire community organizers, policy makers, researchers, students and others to join the happiness 
movement by using survey instruments to measure subjective well-being. The Happiness Alliance's subjective well-being instrument can be used by anyone and is freely available at www.happycounts.org.

\section{References}

Aldrick, P. (2009, September 14). Nicolas Sarkozy wants "well-being" measures to replace GDP. The Telegraph. Retrieved from http://www.telegraph.co.uk/finance/economics/6189582/NicolasSarkozy-wants-well-being-measure-to-replace-GDP.html

Ariely, D. (2010, June). You are what you measure. Harvard Business Review Magazine. Retrieved from http://hbr.org/2010/06/column-you-are-what-you-measure/ar/

Australian Centre on Quality of Life. (n.d.a). About quality of life. Retrieved from http://www.acqol.com.au/index.php

Australian Centre on Quality of Life. (n.d.b). Australian Unity Well-Being Index. Retrieved from http://www.acqol.com.au/reports/auwbi.php

Australian Centre on Quality of Life. (n.d.c). History and overview. Retrieved from http://www.australianunity.com.au/about-us/Wellbeing/Community-wellbeing

Australian Centre on Quality of Life. (n.d.d). Macau quality of life reports (2007-2012). Retrieved from http://www.acqol.com.au/reports/macau.php

Australian National Development Index (ANDI). (2017). The only national framework to capture the essence of national, sustainable well-being. Retrieved from http://www.andi.org.au/the-indexin-a-nutshell.html

Australian Unity. (n.d.). Community well-being. Retrieved from http://www.australianunity.com.au/about-us/Wellbeing/Community-wellbeing

BBC. (2013, July 30). Happiness index shows "small improvement" in 2013, ONS says. BBC News Service. Retrieved from http://www.bbc.com/news/uk-23501423

Big Lottery Fund. (n.d.). Health and well-being. Retrieved from https://www.biglotteryfund.org.uk/research/health-and-well-being\#

Booth, M. (2014, January 24). Copenhagen: The happy capital. The Guardian. Retrieved from http://www.theguardian.com/travel/2014/jan/24/copenhagen-denmark-happy-capital-holiday

Brazil isn't growing: So why are Brazilians so happy? (2013, May 7). The Economist. Retrieved from http://www.economist.com/blogs/economist-explains/2013/05/economist-explains-whybrazilians-happy-slow-growth-brazil

Canadian Index of Well-Being. (n.d). City of Guelf. Retrieved from https://uwaterloo.ca/canadianindex-wellbeing/community-users/city-guelph

Center for Rural Studies at the University of Vermont. (2012, February 22). The Vermont happiness initiative. Retrieved from https://www.uvm.edu/crs/reports/2013/Vermont\%20Happiness\%20Study.pdf

Common Good Vermont Coordinator. (2012, May 31). News: Measure what matters conference recap. Retrieved from http://blog.commongoodvt.org/2012/05/news-measure-what-mattersconference-recap/

Community Indicators Consortium. (2015). Indicator project. Retrieved from http://www.communityindicators.net/projects 
Council Connection. (2011, December 1). Seattle receives first "happiness report card." Retrieved from http://council.seattle.gov/2011/12/01/seattle-receives-first-"happiness-report-card"/

Creston and District Community Directed Funds. (n.d.a). C\&DCDF. Retrieved April 23, 2016, from http://communityfund.ca/about/

Creston and District Community Directed Funds. (n.d.b). Community partners. Retrieved from http://communityfund.ca/better-life-project/community-partners/

Creston and District Community Directed Funds. (n.d.c). Cultivating happiness in Creston and district. Retrieved from http://communityfund.ca/better-life-project/community-partners/

Davey, G., \& Rato, R. (2012). Subjective well-being in China: A review. Journal of Happiness Studies, 13, 333-346. doi: 10.1007/s10902-011-9266-6

Davidson, A. (2015, July 1). The economy's missing metrics. The New York Times Magazine. Retrieved from http://www.nytimes.com/2015/07/05/magazine/the-economys-missingmetrics.html?_r=3

Dickenson, E. (2011, January 3). GDP: A brief history. Foreign Policy. Retrieved from http://foreignpolicy.com/2011/01/03/gdp-a-brief-history/

Dundee, A. (2014, April 17). Measuring and fostering the well-being of European citizens (Document 13539). Council of Europe Parliamentary Assembly. Retrieved from http://assembly.coe.int/nw/xml/XRef/Xref-DocDetails-EN.asp?FileID=20898\&lang=EN

Easterlin, R. (1974). Does economic growth improve the human lot? In P. David \& R. Reder (Eds), Nations and households in economic growth: Essays in honor of Moses (pp. 89-125). New York, NY: Academic Press. Retrieved from http://graphics8.nytimes.com/images/2008/04/16/business/Easterlin1974.pdf

Easterlin, R. (1995). Will raising the incomes of all increase the happiness of all? Journal of Economic Behavior and Organization, 27, 35-48. doi:10.1016/0167-2681(95)00003-B

Easterlin, R. (2001). Income and happiness: towards a unified theory. The Economic Journal, 111, 465-484. doi:10.1111/1468-0297.00646

Fiksel, J., Eason T., \& Fredrickson, H. (2011). A framework for sustainability indicators at EPA. Retrieved from http://cfpub.epa.gov/si/si_public_record_Report.cfm?dirEntryID=254270

Firestone, A. (2012, March 14). TEDx Somerville Part II. The Somerville Times. Retrieved from http://www.thesomervillenews.com/archives/24172

Giovannini, E., Hall, J., \& d'Ercole M. (2007). Measuring well-being and societal progress. Conference Beyond GDP-Measuring progress, true wealth, and the well-being of nations. European Parliament: Brussels. Retrieved from http://citeseerx.ist.psu.edu/viewdoc/summary?doi=10.1.1.371.2897

Gross National Happiness USA (GNHUSA). (n.d.). Gross National Happiness baseline national survey results. Retrieved from http:/gnhusa.org/gross-national-happiness/

Happiness Alliance. (n.d.). About. Retrieved from http://www.happycounts.org/about.html

Happiness Initiative. (2011). Happiness Report Card for Seattle. Retrieved from http://www.slideshare.net/TheHappinessInitiative/seattle-area-happiness-report-card-for2011

Happiness Pulse. (n.d.). Happiness Pulse. Retrieved from https:/happinesspulse.org/ 
Happiness Research Institute. (2014). Happy Danes report. Retrieved from http://www.happinessresearchinstitute.com/download/i/mark_dl/u/4012182887/4617999983/T heHappyDanes.pdf

Happy City. (n.d.). Please complete our survey: Thank you [Mobile application software]. Retrieved February 15, 2015, from http://www.happycityindex.org/long-survey

Happy City. (2016a). Happiness Pulse 2016 report executive summary. Retrieved from http://www.happycity.org.uk/wp-content/uploads/2016/10/HC_Pulse_execsumm5.pdf

Happy City. (2016b). Happy City Index 2016 report executive summary. Retrieved from http://www.happycity.org.uk/wp-content/uploads/2016/10/HCI_execsumm5.pdf

Helliwell, J., Huang, H., \& Wang, S. (2015). The geography of world happiness. In J. Helliwell, R. Layard, \& J. Sachs (Eds.), World happiness report 2015 (p. 32). New York, NY: Sustainable Development Solutions Network. Retrieved from http://worldhappiness.report/overview/

Helliwell, J., Layard, R., \& Sachs, J. (Eds.). (2012). World happiness report. New York, NY: Columbia University Earth Institute. Retrieved from http://worldhappiness.report/wpcontent/uploads/sites/2/2012/04/World_Happiness_Report_2012.pdf

Helliwell, J., Layard, R., \& Sachs, J. (Eds.). (2013). World happiness report 2013. New York, NY: United Nations Sustainable Development Solutions Network. Retrieved from http://unsdsn.org/resources/publications/world-happiness-report-2013/

Holden, M. (2006). Revisiting the local impact of community indicators projects: Sustainable Seattle as prophet in its own land. Applied Research in Quality of Life, 1, 253-277. doi:10.1007/s11482-007-9020-8

Hoornweg, D., \& Bhada-Tata, P. (2012). What a waste: a global review of solid waste management. Washington, DC: World Bank. Retrieved from https://openknowledge.worldbank.org/handle/10986/17388

INEGInforma (Producer). (2014a). Subjective well-being and public policy: Examples and potential use (Meso) - A - (English audio) [Video file]. Panel 3: Subjective Well-Being and Public Policy for the Instituto Nacional de Estadistica y Geografia Conference. Retrieved from http://youtu.be/X_Jm38EV8UQ?list=UUvFp7Fse31ECLPYA4g9xD9A

INEGInforma (Producer). (2014b). Subjective well-being and public policy: Examples and potential use (Meso) - B - (English audio) [Video file]. Panel 3: Subjective Well-Being and Public Policy for the Instituto Nacional de Estadistica y Geografia Conference. Retrieved November 5, 2016, from http://youtu.be/ibitjcjOTIY

Instituto Visão Futuro (IVF). (n.d.). Sugestões para a implementação do FIB. Retrieved from http://www.visaofuturo.org.br/pdfs2/Sugestões\%20para\%20a\%20Implementação\%20do\%20FI B.pdf

International Well-Being Group. (2013). Personal Well-Being Index (5th edition). Melbourne, Australia: Deakin University Centre on Quality of Life. Retrieved from http://www.acqol.com.au/iwbg/wellbeing-index/pwi-a-english.pdf

KCTS9 (Producer). (2011, February 25). Measure of happiness [Video file]. KCTS 9 Connects:183. Retrieved May 1, 2017, from http://video.kcts9.org/video/1822609990/

King 5. (2011, June 20). City Council aims to make Seattle happy [Video file]. King 5 News. [Recorded television news report]. Retrieved from http://www.king5.com/story/news/local/seattle/2014/08/01/12991452/ 
Layard, R. (2007). Happiness lessons from a new science. London, England: Penguin Books.

Local Giving. (2015). The happy city initiative. Retrieved from https://localgiving.com/charity/happycity

Maslow, A., (1943). A theory of human motivation. Psychological Review, 50, 370-396 doi:10.1037/h0054346

Max-Neef, M., Elizalde, A., \& Hopenhayn, M. (1992). Development and human needs. In P. Ekins \& M. Mac-Neef (Eds.), Real-life economics: Understanding wealth creation (pp. 197-213). New York, NY: Routledge. Retrieved from http://alastairmcintosh.com/general/resources/2007Manfred-Max-Neef-Fundamental-Human-Needs.pdf

Musikanski, L. (2014). Happiness in public policy. Journal of Social Change, 6, 55-85. doi:10.5590/JOSC.2014.06.1.06

Musikanski, L. (2015). Measuring happiness to guide public policy making: A survey for instrument and policy initiative. Journal of Social Change, 7, 39-55. doi:10.5590/JOSC.2015.07.1.04

Musikanski, L., Cloutier, S., Bejarano, E., Briggs, D., Colbert, J., Strasser, G., \& Russell, S. (2017). Happiness Index methodology. Journal for Social Change, 8, 4-31. doi:10.5590/JOSC.2017.09.1.02

Musikanski, L., \& Polley, C. (2016). Life, liberty, and pursuit of happiness: Measuring what matters. Journal of Social Change, 7, 48-72. doi:10.5590/JOSC.2016.08.1.05

Nesh Fotos e Videos (Producer). (2012, May 31). GNH's pilot project in Brazil [Video file]. Retrieved from http://www.youtube.com/watch?v=FPeNwH3ax-c\&feature=youtu.be

O’Donnell, G. (2013). Using well-being as a guide to policy. In J. Helliwell, R. Layard, \& J. Sachs (Eds.), World happiness report 2013. New York, NY: United Nations Sustainable Development Solutions Network. Retrieved from http://unsdsn.org/resources/publications/world-happiness-report-2013/

Office for National Statistics. (n.d.). Measuring national well-being. Retrieved from http://www.ons.gov.uk/ons/guide-method/user-guidance/well-being/index.html

Pendery, D. (2015). The Taiwanese student happiness initiative: fulfilling lives and success in the future. Journal for Social Change, 7, 1-12. doi:10.5590/JOSC.2015.07.1.01

Polley, C. (2012). Metaphors for happiness in English and Chinese (Doctoral dissertation). Retrieved from http://www.academia.edu/2238467/Metaphors_for_happiness_in_English_and_Mandarin_Chi nese_PhD_dissertation_

Rato, R., \& Davey, G. (2012). Quality of life in Macau, China. Social Indicators Research, 105, 93108. doi:10.1007/s11205-010-9766-5

SERI, Global 2000, \& Friends of Earth Europe. (2009). Overconsumption? Our use of the world's natural resources. Retrieved from http://www.foeeurope.org/sites/default/files/publications/foee_overconsumption_0909.pdf

SomervilleMA.gov. (2011). A report on well-being. Retrieved from http://munishare.org/?wpdmdl=47

Stevens, M. (2013, March 13). Santa Monica gets $\$ 1$ million to measure residents' well-being. Los Angeles Times. Retrieved from http://articles.latimes.com/2013/mar/13/local/la-me-well-being20130314 
The Well-Being Project. (n.d). Measuring what matters most. Retrieved from http://wellbeing.smgov.net/about/wellbeing-index

The Well-Being Project. (2014). Santa Monica Well-Being Survey 2014 [Mobile application software]. Unpublished Instrument. Retrieved October 13, 2014, from http://wellbeing.smgov.net/

Victoria Foundation. (n.d.). Partnership. Retrieved from http://www.victoriafoundation.bc.ca/happiness-index/partnership

Victoria Foundation. (2009). Reports and publications. Retrieved from http://www.victoriafoundation.bc.ca/happiness-index/reports-and-publications

VisitDenmark. (n.d.). Happiest people in the world? Retrieved from http://www.visitdenmark.co.uk/en-gb/denmark/art/happiest-people-world

Walsh, Z. (2013, June). The science of Sukha: scientific theory of the Buddhist concept of happiness and human development (Master's thesis). Retrieved from https://www.academia.edu/5573123/The_Science_of_Sukha_A_Scientific_Theory_on_the_Bud dhist_Concept_of_Happiness_and_Human_Development

Whitby, A., Seaford, C., Berry, C., \& BRAINPOoL Consortium Partners. (2014, March 31). BRAINPOoL project final report: Beyond GDP: from measurement to politics and policy. BRAINPOoL Deliverable 5.2, A collaborative programme funded by the European Union's Seventh Programme for research, technological development and demonstration under Grant Agreement No. 283024. World Future Council. Retrieved from http://www.brainpoolproject.eu/wp-content/uploads/2014/05/BRAINPOoL-Project-FinalReport.pdf

World Bank. (2015). Overview. Retrieved November 5, 2016, from http://www.worldbank.org/en/country/brazil/overview

Zhang, J., \& Norvilitis, J. (2002). Measuring Chinese psychological well-being with western developed instruments. Journal of Personality Assessment, 79, 492-511. doi:10.1207/S15327752JPA7903_06 


\section{Appendix A \\ Happiness and Well-Being Surveys in Other Areas}

This appendix covers community efforts to measure happiness and well-being using survey instruments that reinforce the lessons identified in this essay. It covers ten areas listed in alphabetical order. The intent of this appendix is to provide additional resources and information for community organizers, students, researchers and policy makers inspired to measure happiness and well-being and join the happiness and well-being movement.

\section{Copenhagen, Denmark}

In Copenhagen, the Happiness Research Institute, a nonprofit, issued the Happy Danes Report in 2014. It analyzed aspects of happiness data collected from various sources and identifies policies, programs, and projects that their research indicates are highly correlated to satisfaction with life and feelings of happiness. The report draws from many data sources, ranging from the OECD Better Life Index, to Danish pension and life insurance company Danica Pension's happiness survey of about 10,000 Danes (Happiness Research Institute, 2014).

The Happy Danes Report identifies governmental policies that are the basis for people's happiness. These include public policy programs including (a) access to preventative and traditional healthcare, (b) assistance for elders, (c) democratic institutions such as political festivals, (d) ensuring all who want a job have a job, (e) low cost housing for students, (f) the highest government spending on social policy relative to national expenditure in the world, and (g) vacation and sick leave laws. Cultural qualities identified in the Happy Danes Report include (a) high degrees of autonomy at work, (b) high levels of volunteering, (c) high valuing of social relationships as evidenced by the habit of people visiting with friends at least once a week on average, (d) low levels of workaholism, (e) societal support of parents as demonstrated by the practice of leaving a baby in a stroller outside a store while a parent shops, and (f) trust in people as evidenced by self-service food stands.

Denmark has a reputation for being one of the happiest countries in the world (VisitDenmark, n.d). An informal survey asking residents what it was about Copenhagen that makes them happy conducted by Booth (2014) indicates there is little distinction between city and national level factors leading to well-being. This factor could potentially act as a disincentive for community-based happiness indicator efforts at the neighborhood, city, or regional level.

\section{Guelph, Ontario, Canada}

In Guelph, the Canadian Index of Well-Being, a nonprofit, formed a set of subjective indicators of well-being for the mayor of the city of Guelph, using an index that drew from the Happiness Alliance's Happiness Index in 2013 (M. Hilbrecht, personal communication, September 6, 2013). The Canadian Index of Well-Being conducted a survey of the citizens of Guelph, and was working with city policy makers to use the results, when elections resulted in a change in administration (Canadian Index of Well-Being, n.d.). The new administration terminated the indicator project, and all references to it on the city website were deleted under orders from the new mayor (B. Smale, personal communication, October 16, 2016). 


\section{Macau, China}

In Macau, the Macau Quality of Life Report considered happiness and well-being in the city of Macau between 2007 and 2012 (Rato \& Davey, 2012). Quarterly surveys were taken over a 3-year period in Macau from 2007 to 2009, providing a longitudinal perspective on subjective well-being at a community level (Rato \& Davey, 2012). In 2012, the Macau Quality of Life Report began using a measurement scale called the Personal Well-Being Index, developed by the International Well-Being Group (Davey \& Rato, 2012) in Australia. The measurement of Personal Well-Being Index in Macau measures eudemonia and satisfaction with life, as well as the domains of community, health, safety, security, social support, spirituality, and standard of living.

Like Melbourne's Australian Unity Well-Being Index, the Macau Quality of Life Report was a public-private partnership between business and academics. The company involved provided consulting services and published a business magazine, and the data was collected by scholars and used for publication (Australian Center on Quality of Life, n.d.d).

\section{Municipalities of Mexico}

In Municipalities of Mexico, Fundación Imagina, a nonprofit, worked with the University of Puebla to conduct a survey of 26,500 people in 100 municipalities across Mexico in 2012. The survey instrument included life evaluation and affect questions as well as questions about the domains of community, culture, economy, education, environment, health, government, safety, social support, spirituality work, time balance, and work (INEGInforma, 2014a). The data was used to inform over 20 social and economic governmental programs that ranged from daycare centers, family development programs, and financial benefits to workshops for the elderly (INEGInforma, 2014a).

\section{San Pedro, Mexico}

In San Pedro, García of the University of Monterrey worked with the San Pedro Municipality to conduct a subjective well-being survey in 2008 and 2011(INEGInforma, 2014b). They used to the data to identify populations suffering from economic deprivation, and identify interventions that alleviate the negative social, political or emotional impacts that are exacerbated or caused by income inequality (INEGInforma, 2014b). Their survey included questions about personal well-being as well as the domains of community, education, economy, family, government, health, leisure, security, and work (INEGInforma, 2014b). The result of the survey informed the municipality's social policy agenda (INEGInforma, 2014b).

\section{Santa Monica, California, United States}

In Santa Monica, the mayor was awarded one million dollars by the Bloomberg Philanthropies' Mayors Challenge to become the first mayor to measure happiness in 2013 (Stevens, 2013). The city created an index that included objective data from the city's database, social media data, and a survey. The project is called The Well-Being Project. The survey measured affect, eudemonia, and satisfaction with life (using the Cantril Ladder), as well as the domains of community services, culture, environment, eudemonia, neighborhoods, safety, time balance, and work (The Well-Being Project, 2014). The city conducted the survey in 2014 and 2016. They issued an online report for the 2014 survey data organized in to seven areas: community, demographics, economic opportunity, health, learning, place, and outlook (The Well-Being Project, n.d.). To date, Santa Monica's Well- 
Being Project does not appear to contemplate the application of happiness and well-being data to city policy.

\section{Seattle, Washington, United States}

In Seattle, Sustainable Seattle, a nonprofit that was one of the first organizations to create regional sustainability indicators (Holden, 2006), worked with the Seattle City Council to measure citywide happiness in 2011 and issue a report (Happiness Initiative, 2011). The project was inspired by the efforts of Victoria (KCTS9, 2011).

In 2010, Seattle City Council issued a happiness proclamation (King 5, 2011) that included plans to use happiness data to inform policy and budgeting decisions (KCTS9, 2011). The goals of the effort at the onset were to provide data for Seattle policy makers (Happiness Initiative, 2011) and to provide a replicable model for campuses, cities, communities, and companies, as Sustainable Seattle had done in the 1990s (Holden, 2006). In 2011, the Seattle City Council used the report to inform budgeting decisions, including not closing down community centers in spite of citywide budget cuts (R. Conlin, personal communication, November 14, 2011). By late 2011, other areas had launched their own efforts to measure happiness using the same survey instrument (Council Connection, 2011).

The effort spun off from Sustainable Seattle in 2012 to become a nonprofit, the Happiness Alliance (Happiness Alliance, n.d.). The Happiness Alliance was formed, in part, to provide resources, including a survey instrument measuring subjective well-being freely online. Four other communitybased efforts using these resources (undertaken in Creston, Vermont, and Taiwan) are included in this essay and this appendix.

\section{Somerville, Massachusetts, United States}

In Somerville, the mayor's office formed a subjective well-being index that included questions about affect and overall satisfaction with life, as well as the domain of community services in 2011 (SomervilleMA.gov, 2011). The mayor's office issued the Somerville, MA: A Report on Well-Being in 2011. The report was issued with extensive media coverage (SomervilleMA.gov, 2011), and a TEDx event (Firestone, 2012). The mayor's office used the data to allocate resources to the traffic and parking departments and to inform "new policies and important policy considerations for the future" (SomervilleMA.gov, 2011, p. 13).

\section{Republic of China (Taiwan)}

In Taiwan, Pendery (2015), a professor concerned for the well-being of his students, conducted a convenience sampling of students at four different universities using the Happiness Alliance's survey instrument in 2014. The data was analyzed and reported in an article, with suggested policies for the four university administrations (Pendery, 2015).

Also in Taiwan, Walsh (2013), a graduate student, used the Happiness Alliance's survey instrument to examine the impact of Buddhism on individual and cultural happiness in 2011. The survey instrument was administered to students of Buddhism and to the general student body on one campus in Taiwan. Data gathered on a campus in the United States were included in the analysis. Walsh concludes his study as the "first-known evidence of Buddhism's promotion of happiness" (p. 123) of its kind. 


\section{Victoria, British Columbia, Canada}

In Victoria, the mayor was joined by various organizations including the health authority, university, and the Victoria Foundation to survey the city using a version of Bhutan's GNH Index in 2009 (Victoria Foundation, n.d.). A public meeting was held in which the data was shared with the public and an artist recorded the proceedings in drawings (K. Stratford, personal communication April 11, 2011). Victoria Foundation used the data for its annual report (Victoria Foundation, 2009). 


\section{Appendix B}

Poster of Cultivating Happiness in Creston and District Process (Creston and District Community Directed Funds, n.d.c)

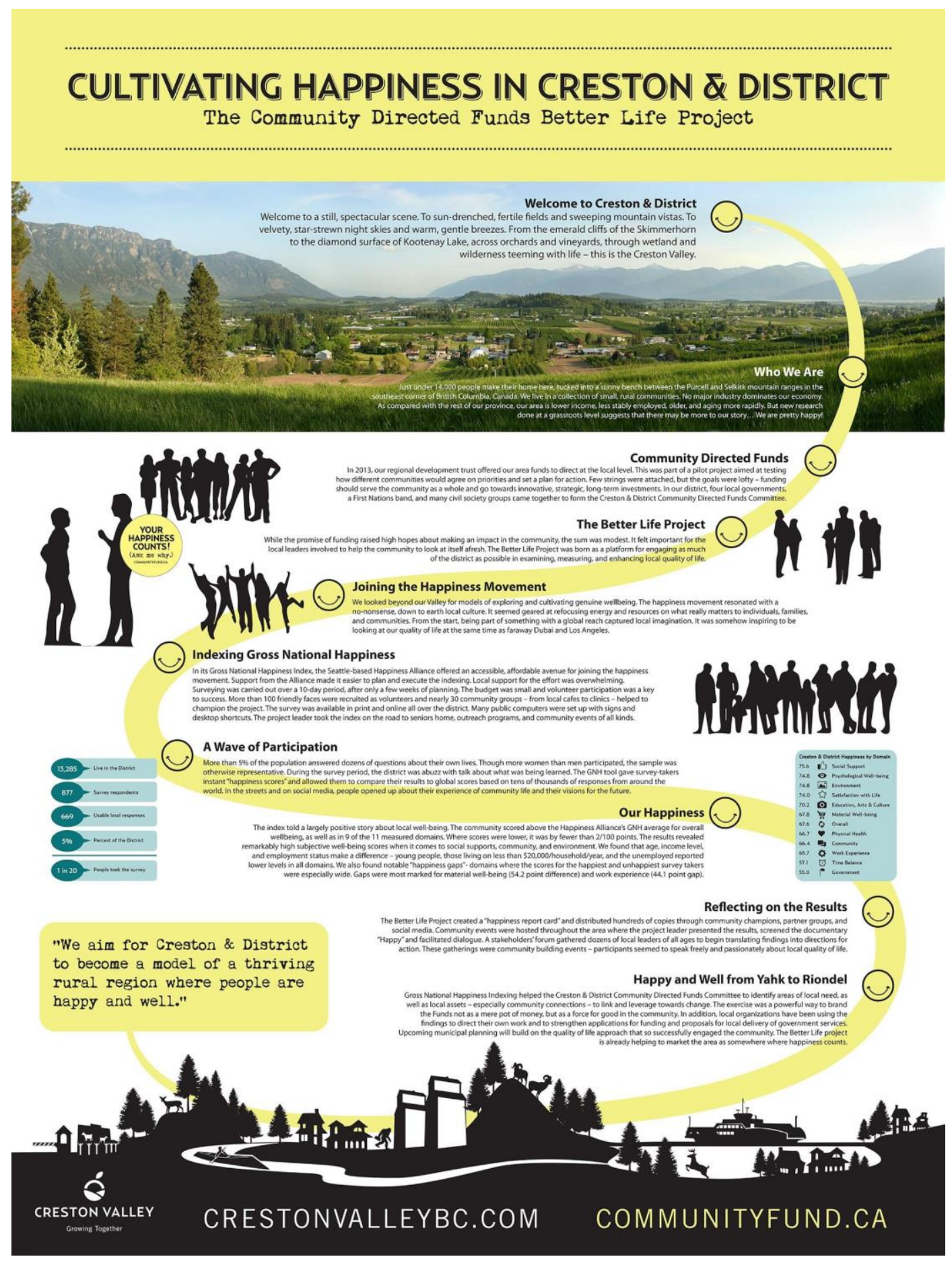


The Journal of Social Change, sponsored by Walden University, welcomes manuscripts focusing on interdisciplinary research in social change that improves the human condition and moves people, groups, organizations, cultures, and society toward a more positive future.

Walden University Publishing: http://www.publishing.waldenu.edu 